\title{
STUDIES OF TOTAL BODY WATER WITH TRITIUM ${ }^{1,2}$
}

\author{
BY T. C. PRENTICE, W. SIRI, N. I. BERLIN, G. M. HYDE, R. J. PARSONS, \\ E. E. JOINER, AND J. H. LAWRENCE \\ (From the Section on Experimental Medicine, Donner Laboratory, University of California, \\ Berkeley, and the Highland Alameda County Hospital, Oakland, Cal.)
}

(Submitted for publication November 5, 1951 ; accepted February 11, 1952)

The precise measurement of total body water in man by in vivo methods is becoming increasingly important as more is learned of the significance of electrolyte and water metabolism in normal and pathologic states. While there is as yet insufficient evidence to suggest that body water determinations per se will prove of significant value in diagnosis and therapy, the investigation of body water appears essential to a fuller understanding of disease states in which electrolyte and water balance is altered. Thus far, such measurements remain largely laboratory experiments with the bulk of the data obtained from normal subjects. However, with the present improvements in the methods for assaying tritium, either with the ionization chamber (1) or the proportional counter (2), the study of total body water and water metabolism by tracer methods will doubtless be greatly accelerated.

The present study was undertaken to develop further the use of tritium for routine body water measurement and to extend the investigation of total body water to a variety of disease states. A rapid method for routine assay of tritium had already been developed in this laboratory, but there still remained several factors which, $a$ priori, could influence the accuracy of total body water determinations with tritium labeled water. The time required for complete mixing throughout the body water following intravenous administration of tritium labeled water was considered particularly important in selecting the time at which blood samples could be taken to determine the amount of dilution. It was also of special interest to investigate the possible existence of a significant isotope

\footnotetext{
1 This work was supported by the Life Insurance Medical Research Fund and the U. S. Atomic Energy Commission.

2 We are grateful to Dr. Leo Stanley, of the California State Prison at San Quentin, and to volunteers from the prison who served as subjects for the normal, middle-aged male group.
}

effect as well as to evaluate by more direct methods, the magnitude of the error introduced by exchange of tritium with the solid constituents of the body.

Total body water has been measured by many investigators using four principal methods: 1) post-mortem desiccation of cadavers $(3), 2)$ balance studies of electrolytes and water $(4), 3$ ) determination of the specific gravity of the whole body in vivo $(5,6)$ and 4$)$ the dilution of various substances presumed to be limited to and uniformly mixed within the body water. Well documented reviews of the literature have recently appeared $(5,7)$.

Method 1) has no practical significance in clinical investigation. Method 2) requires painstaking balance experiments and no claim is made for quantitative accuracy. Method 3), the measurement of whole body specific gravity, has received considerable recent attention. It is based on the premise that the body can be divided into two portions, namely, the fat-free portion, called the lean body mass, and adipose tissue. The lean body mass purportedly maintains a relatively constant gross composition, thus contributing a constant known effect to whole body specific gravity. The fat content, on the contrary, varies widely from individual to individual and is normally the largest factor responsible for the variation of body density. This basic premise has been substantiated by careful work in guinea pigs and rats $(5,8)$. In large groups of these animals, whole body specific gravity was measured and thereafter total body fat determined gravimetrically. A hyperbolic relationship between specific gravity and body fat was found which agreed closely with the curve predicted from theoretical considerations (9). The equation for this curve in humans, $\%$ fat $=100$ $\times\left(\frac{5.548}{\mathrm{sp} \cdot \mathrm{gr} \text {. }}-5.044\right)$, provides a reasonably accurate estimate of total body fat when the specific gravity 
can be measured. Since water constitutes, on the average, $73 \%$ of the fraction remaining after subtracting fat, then $\%$ body water $=0.73(100-\%$ fat). The validity of this method in clinical investigation should be questioned from two standpoints. First, since all the experimental work was done in guinea pigs and rats, can the results be extrapolated to man? Comparisons of total body water estimated by this method with values obtained using tritium (10) or antipyrine (6) agree closely on the average in normal man. Second, is the method valid for estimating total body water during disease states? Experimental work is lacking on this point, but the marked changes which frequently occur both in the distribution and in the amounts of many body constituents during disease, coupled with the dependency of this method on constant composition of the lean body mass, make it unlikely that accurate results could be obtained using this method alone.

The most direct, and potentially the most accurate method of measuring total body water is the dilution method. Many substances have been tested, but most have proved unsatisfactory because of failure to limit themselves to and distribute themselves equally throughout body water. Deuterium (11), tritium (12), and antipyrine $(13,14)$ have been used most successfully thus far. Aside from differences in technical difficulties, which for deuterium are often considerable, deuterium and tritium are equivalent. Both give body water volumes which appear to be slightly greater than the true volume because of exchange with hydrogen in protein. Antipyrine, on the other hand, requires serial sampling in order to compensate for its relatively rapid disappearance from plasma.

\section{METHODS}

A total of 57 subjects, including both normals and those with disease states, were used in the present study. Thirty-seven of the subjects were patients with cardiac, liver, and blood abnormalities. Normal subjects were selected primarily in the middle age range inasmuch as previous studies were made predominantly in relatively young, active subjects. Among the normal subjects, 15 were in the age group of 34 to 56 years. Four of the five remaining normal subjects were 20 to 25 years of age.

The tritiated water used throughout the study was prepared as a stock solution with a specific activity of approximately $2 \mathrm{mc}$./cc. One $\propto c$. of the sterilized stock solution was given intravenously with a tuberculin syringe. It should be noted that the use of tuberculin syringes for this purpose has sometimes been criticized on the grounds that they are not sufficiently reliable for delivering an accurately known volume of fluid, particularly when the same syringe is not used throughout a series of injections. This criticism was tested in the present instance by gravimetric determination of the volume of water delivered by tuberculin syringes selected at random. Although the test cannot be regarded as exhaustive, the syringes tested showed a maximum error of no more than $2 \%$ in the $1 \mathrm{cc}$. volume delivered, while the variation in volume delivered from any single syringe did not exceed $0.5 \%$. This result is in agreement with similar tests made in this laboratory to assess the error in tuberculin syringes used for blood volume determination with $\mathrm{P}^{23}$ labeled red cells.

Following administration of the tritiated water, heparinized blood samples were withdrawn at intervals of two, four, and six hours. The plasma was separated by centrifugation, placed in sealed tubes and frozen until analyzed. At two hours, mixing appeared in every case to be complete, and if differences in plasma tritium concentration did exist at the two later intervals, such changes were within the experimental error; consequently, the values of the specific activities of the three plasma samples were averaged. An earlier practice of taking samples at three, six, and 24 hours, with the intention of extrapolating the specific activity of plasma to the time of injection was abandoned in patients without fluid retention in view of the relatively long turnover time of about ten days for water in humans (12). Nevertheless in all patients with edema or any collection of fluid in the serous cavities the three, six and 24 hour time periods for sampling were used. It was felt that averaging the two, four, and six hour samples was more reliable than the extrapolation from samples taken over the longer intervals in patients in whom fluid retention was not present.

The tritium activity was assayed with $100 \mathrm{cc}$. cylindrical ionization chambers which were filled to atmospheric pressure with hydrogen generated from $0.5 \mathrm{cc}$. of plasma sample. Reduction of the water was effected in vacuo with lithium aluminum hydride dissolved in diethyl carbitol (1-ethoxy-2-[B-ethoxyethoxy] ethane) as described by Siri. The rate of ionization was measured with a vibrating reed electrometer and recording potentiometer.

A tritium standard, prepared by diluting a portion of the stock solution by a factor of 20,000 , was run in each ionization chamber at frequent intervals. Total body water volumes were computed from the simple dilution formula: $20 \times$ specific activity of standard/specific activity of plasma $=$ total body water in liters. These are the volumes given in Tables II to V inclusive, and do not include the small correction for hydrogen exchange discussed later because the correction is that for an idealized "average" man. The correction would vary somewhat with each individual, depending upon the ratio of water to lean tissue. 
Antipyrine, used for body water volume comparisons, was prepared as a sterile solution of $0.9 \mathrm{gm}$. antipyrine in $45 \mathrm{cc}$. water and the whole given intravenously. Heparinized blood samples were taken at the same time as those for the tritium assay, namely, at two, four, and six hours. Plasma antipyrine levels were determined by the method described by Brodie, Axelrod, Soberman, and Levy (13), using a Beckman DU spectrophotometer. The plasma concentration of antipyrine, in contrast with that of tritiated water, exhibits a relatively rapid exponential disappearance with an average half time of about 11 hours; consequently, the correct dilution factor must be found by extrapolating the plasma concentration curve back to the time of injection.

The exchange of tritium with hydrogen in tissue solids was determined from the uptake of tritium in a representative selection of organs of rabbits. Each of four rabbits was injected with $0.1 \mathrm{mc}$. of tritium and exsanguinated after three hours. Plasma was assayed directly for tritium, while samples of plasma solids, muscle, liver, kidney, G.I. tract, and fat were first dried in vacuo to constant weight before analysis. For tritium assay, the dried solids were oxidized to water in a stream of oxygen in a quartz tube and passed over copper oxide at $850^{\circ} \mathrm{C}$. The water collected in a $\mathrm{CO}_{2}$ trap was then analysed for tritium as before.

\section{OBSERVATIONS}

Arterial mixing of tritiated water, investigated in this laboratory by Pace and associate (15), reveals that mixing is essentially complete in normal adults well within two hours. In the present investigation, early changes in the specific activity of tritium in plasma were studied serially in two patients with marked ascites in whom mixing might be expected to be greatly altered. However, as shown in Figure 1, after two hours, mixing appears to be complete, at least within the accuracy of measurement, in both these individuals. Subsequent studies in patients with fluid retention indicate that long halftime mixing components are present. However, in the present studies the 24 hour sample taken in patients with fluid retention minimizes any error due to slow mixing components.

In simple dilution methods such as those used here, where equilibrium is first established, it is highly unlikely that even the great mass difference between hydrogen and tritium can introduce an isotope effect of consequence. However, without direct comparison with deuterium, this is difficult to demonstrate. The comparison, nevertheless, could be made indirectly with the results of studies in which antipyrine and deuterium water volumes were investigated. If no isotope effects were pres-

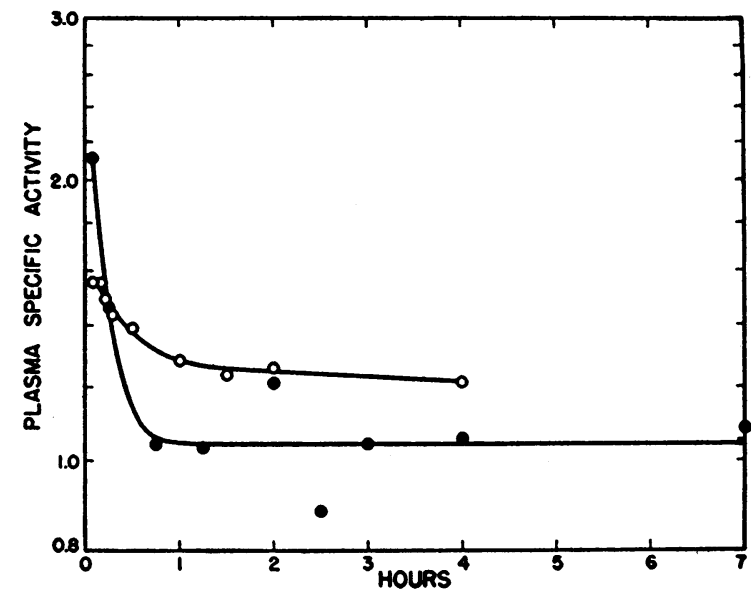

Fig. 1. Tritium Concentration in Venous Blood as a Function of Time in Two Patients wite CirRHOSIS OF THE LIVER AND Ascites

Plasma specific activity is expressed in units of activity relative to the tritium standard.

ent, the ratios ( $\mathrm{H}^{3}$ body water)/(antipyrine body water) and $\left(\mathrm{H}^{2}\right.$ body water)/(antipyrine body water) should be equal. This was, in fact, observed on comparing the present tritium-antipyrine body water volumes with the deuterium-antipyrine body water volume reported by Soberman and associates (14). At least within the present experimental error, an isotope effect does not appear to be a measurable factor.

Previous investigators (14) have observed that on the average, a small but relatively constant difference in total body water is found with deuterium as compared to antipyrine. As indicated above, a similar difference between tritium and antipyrine water volumes is found in which the tritium dilution volume is slightly greater than that for antipyrine: This difference can be accounted for by exchange of tritium with labile hydrogen atoms of proteins and carbohydrates. The body water (plasma) specific activity is consequently lowered, giving the appearance of larger volume. As shown in Table $I$, the specific activity of tritium in various organs of the rabbit varied from $6 \%$ to $15 \%$ of that for body water. This agrees closely with the observations of Ussing with deuterium (16). Assuming that exchange of the same order of magnitude as in rabbits also takes place in the corresponding tissue of man, a correction of about $2 \%$ in total body water can be calculated, which is in agree- 
TABLE I

Exchange of tritium in tissues relative to body water.

Except for plasma, all tissues were first dried to constant weight before analysis for tritium. The values given in the table are adjusted to a specific activity of 100 for plasma (body water), and are expressed as activity (in arbitrary units) per gram of tissue or plasma.

\begin{tabular}{l|r|r|r|r}
\hline \multirow{2}{*}{ Organ } & \multicolumn{4}{|c}{ Rabbit } \\
\cline { 2 - 5 } & \multicolumn{1}{|c|}{ I } & \multicolumn{1}{|c|}{ II } & \multicolumn{1}{c}{ III } & IV \\
\hline Plasma & 100.0 & 100.0 & 100.0 & 100.0 \\
Liver & 14.0 & 10.0 & 15.4 & \\
Kidney & 13.4 & 8.9 & 13.6 & \\
G. I. tract & 8.0 & 7.5 & 11.9 & \\
Muscle & 8.0 & 5.9 & 11.8 & 15.2 \\
Plasma solids & 15.4 & 15.0 & 0 & 15 \\
Fat & - & - & 0 & \\
\hline
\end{tabular}

ment with estimates of $0.5 \%$ to $2.0 \%$ by other investigators (11).

The rabbit data in Table $I$ indicate a difference in lability of hydrogen atoms in various tissue masses of the body. No exchange could be detected in fat. Liver, kidney, and plasma solids show a consistently higher percentage of exchange than do muscle and G.I. tract. This division corresponds more or less with viscera and carcass, and for the purpose of estimating a correction for hy-

TABLE II

Comparison of total body water obtained with tritium and antipyrine in patients and normals

\begin{tabular}{|c|c|c|c|c|c|c|c|}
\hline Subject & Age & Sex & $\begin{array}{c}\mathrm{H}^{2} \text { body } \\
\text { water } \\
\text { (lilers) }\end{array}$ & $\begin{array}{c}\mathbf{H}^{3} \text { body } \\
\text { water } \\
(\%)\end{array}$ & $\begin{array}{l}\text { Anti- } \\
\text { pyrine } \\
\text { body } \\
\text { water } \\
\text { (liters) }\end{array}$ & $\begin{array}{c}\text { Anti- } \\
\text { pyrine } \\
\text { body } \\
\text { water } \\
(\%)\end{array}$ & Diagnosis \\
\hline
\end{tabular}

A. Patients

\begin{tabular}{l|l|l|l|l|l|l|l}
\hline P. C. & 64 & $\mathrm{M}$ & 35.2 & 55.3 & 33.1 & 52.0 & Poly. vera \\
L. Y. & 66 & $\mathrm{~F}$ & 26.8 & 50.0 & 25.3 & 47.2 & Poly. vera \\
T. F. & 63 & $\mathrm{M}$ & 40.6 & 67.1 & 39.4 & 65.2 & Poly. vera \\
B. L. & 76 & $\mathrm{M}$ & 35.6 & 51.0 & 33.7 & 48.4 & Poly. vera \\
S. B. & 59 & $\mathrm{~F}$ & 30.0 & 50.0 & 29.0 & 48.4 & Lymph. leuk. \\
B. A. & 63 & $\mathrm{M}$ & 49.6 & 65.1 & 48.8 & 64.1 & Lymph. leuk. \\
T. C. & 40 & $\mathrm{M}$ & 47.6 & 65.7 & 50.0 & 68.9 & Myel. leuk. \\
D. A. & 63 & $\mathrm{M}$ & 44.0 & 48.8 & 42.6 & 46.8 & Sec. poly. \\
M. B. & 46 & $\mathrm{~F}$ & 28.2 & 59.6 & 26.5 & 56.1 & Congest. fail. \\
B. A. & $\mathbf{5 0}$ & $\mathrm{F}$ & 20.2 & 49.3 & 20.1 & 48.8 & Cirrhosis \\
\hline Mean & $\mathbf{5 9 . 0}$ & & $\mathbf{3 5 . 8}$ & $\mathbf{5 6 . 2}$ & $\mathbf{3 4 . 8}$ & $\mathbf{5 4 . 6}$ & \\
\hline S. D. & & & & \pm 7.5 & & \pm 8.7 & \\
\hline
\end{tabular}

B. Normal subjects

\begin{tabular}{|c|c|c|c|c|c|c|}
\hline $\begin{array}{l}\text { J. M. M. } \\
\mathbf{R} . \mathbf{N} . \\
\mathbf{P} . \mathbf{K} . \\
\mathbf{R} . \mathbf{C} . \\
\text { C. G. }\end{array}$ & $\begin{array}{l}22 \\
25 \\
22 \\
20 \\
55\end{array}$ & $\begin{array}{l}\mathbf{M} \\
\mathbf{M} \\
\mathbf{M} \\
\mathbf{M} \\
\mathbf{M}\end{array}$ & $\begin{array}{l}41.5 \\
43.4 \\
55.0 \\
48.6 \\
40.6\end{array}$ & $\begin{array}{l}60.5 \\
57.5 \\
60.4 \\
63.0 \\
53.3\end{array}$ & $\begin{array}{l}39.4 \\
39.5 \\
51.2 \\
47.4 \\
40.5\end{array}$ & $\begin{array}{l}57.4 \\
55.4 \\
56.2 \\
61.4 \\
53.1\end{array}$ \\
\hline Mean & 28.8 & & 45.8 & 58.9 & 43.6 & 56.1 \\
\hline S.D. & & & & \pm 3.7 & & \pm 3.6 \\
\hline
\end{tabular}

drogen exchange, no large error is introduced by considering the entire viscera as high activity tissue and carcass, generally, as representing the less labile tissue. An average value of $64 \%$ body weight was taken for total carcass, $24 \%$ for total viscera and $12 \%$ was considered fat in a "standard" man. Since adipose tissue contains little water, the true body water should equal $73 \%$ of the lean body mass. The observed body water is greater than this by the water equivalent of the tritium which exchanges in protein (carbohydrates are not considered here because they constitute but

TABLE III

Total body water of normal male subjects

Total body water was measured with tritium labeled water.

\begin{tabular}{l|l|l|c|c|c}
\hline \hline Subject & Age & Height & $\begin{array}{c}\text { Weight } \\
\left(K_{g .}\right)\end{array}$ & $\begin{array}{c}\text { Body } \\
\text { water } \\
\text { (libers) }\end{array}$ & $\begin{array}{c}\text { Body } \\
\text { water } \\
(\%)\end{array}$ \\
\hline 1 & 44 & $5^{\prime} 6^{\prime \prime}$ & 54.1 & 29.7 & 54.7 \\
2 & 40 & $6^{\prime}$ & 91.4 & 43.9 & 48.1 \\
3 & 54 & $5^{\prime} 11^{\prime \prime}$ & 70.5 & 35.2 & 50.0 \\
4 & 42 & $5^{\prime} 10^{\prime \prime}$ & 91.0 & 46.8 & 51.4 \\
5 & 38 & $5^{\prime} 8^{\prime \prime}$ & 77.8 & 40.8 & 52.6 \\
6 & 41 & $5^{\prime} 7^{\prime \prime}$ & 68.2 & 38.7 & 56.7 \\
7 & 42 & $5^{\prime} 8^{\prime \prime}$ & 84.0 & 44.4 & 52.7 \\
8 & 47 & $6^{\prime}$ & 75.5 & 38.5 & 50.6 \\
9 & 53 & $5^{\prime} 7^{\prime \prime}$ & 59.5 & 33.9 & 56.7 \\
10 & 34 & $5^{\prime} 5^{\prime \prime}$ & 67.5 & 34.9 & 51.7 \\
11 & 41 & $4^{\prime} 8^{\prime \prime}$ & 75.5 & 37.1 & 49.1 \\
12 & 53 & $6^{\prime} 1^{\prime \prime}$ & 88.6 & 46.9 & 52.7 \\
13 & 45 & $5^{\prime} 8^{\prime \prime}$ & 73.1 & 36.6 & 49.9 \\
14 & 37 & $5^{\prime} 10^{\prime \prime}$ & 78.2 & 44.2 & 56.5 \\
15 & 56 & $5^{\prime} 11^{\prime \prime}$ & 86.0 & 40.6 & 47.9 \\
\hline Mean & 44.5 & $5^{\prime} 8^{\prime \prime}$ & 76.0 & 39.5 & 52.1 \\
\hline S.D. & & & & & \pm 3.0 \\
\hline
\end{tabular}

a small fraction of the total organic constituents). Thus, observed body water per cent $=73 \%+$ relative specific activity of carcass proteins $\times$ per cent of body weight + relative specific activity of viscera $\times$ per cent of body weight.

The second term on the right is :

$$
\begin{aligned}
0.08 \times 0.795 \times & 0.27 \times 56.5 \\
& =0.96 \% \text { of body weight, }
\end{aligned}
$$

while the third term is :

$$
\begin{aligned}
0.13 \times 0.795 \times & 0.27 \times 24 \\
& =0.67 \% \text { of body weight. }
\end{aligned}
$$

Where 0.08 and 0.13 are the relative specific activities for carcass and viscera, 0.795 is the fraction of protein in dry, fat-free tissue found by 
TABLE IV

Total body water of cardiac patients with and without failure

All body water determinations were made with tritium labeled water.

\begin{tabular}{|c|c|c|c|c|c|c|}
\hline Patient & Age & Sex & $\begin{array}{l}\text { Weight } \\
\left(K_{\text {K. }}\right)\end{array}$ & $\underset{\text { (liters) }}{\text { Body water }}$ & $\begin{array}{l}\text { Body water } \\
(\%)\end{array}$ & Diagnosis \\
\hline \multicolumn{7}{|c|}{ A. Compensated at bed rest } \\
\hline $\begin{array}{l}\text { M. K. (2) } \\
\text { B. F. } \\
\text { W. G. } \\
\text { C. R. (2) }\end{array}$ & $\begin{array}{l}34 \\
47 \\
80 \\
38\end{array}$ & $\begin{array}{l}\mathbf{F} \\
\mathbf{M} \\
\mathbf{F} \\
\mathbf{F}\end{array}$ & $\begin{array}{l}46.0 \\
70.4 \\
60.5 \\
54.5\end{array}$ & $\begin{array}{l}28.0 \\
43.0 \\
29.6 \\
29.8\end{array}$ & $\begin{array}{l}61.0 \\
61.0 \\
49.0 \\
54.6\end{array}$ & $\begin{array}{l}\text { H.C.V.D. } \\
\text { H.C.V.D. with uremia } \\
\text { A.S.H.D. } \\
\text { H.C.V.D. }\end{array}$ \\
\hline Mean & 49.8 & & 57.8 & 32.6 & 56.4 & \\
\hline S.D. & & & & & \pm 5.8 & \\
\hline
\end{tabular}

B. With peripheral edema

\begin{tabular}{l|l|l|l|l|l|l}
\hline B. A. & 45 & F & 46.8 & 26.5 & 56.6 & Rheum. ht. disease \\
C. P. & 71 & M & 59.6 & 33.6 & 56.4 & A.S.H.D. \\
A. G. & 62 & M & 73.4 & 44.0 & 60.0 & H.C.V.D. \\
M. S. & 74 & F & 78.5 & 27.6 & 35.2 & H.C.V.D. (very obese; little \\
D. M. & 61 & F & 69.4 & 34.0 & 49.0 & edema) \\
P. D. & 47 & M & 70.0 & 41.7 & 59.5 & Rh. pulmonale \\
H. M. & 44 & F & 56.7 & 53.2 & 65.0 & H.C.V.D. \\
S. W. & 40 & F & 55.5 & 36.9 & 66.5 & H.C.V.D. \\
\hline Mean & 55.5 & & 63.7 & 37.1 & 56.0 & \\
\hline S.D. & & & & & \pm 10.6 & \\
\hline
\end{tabular}

C. With pulmonary congestion but no peripheral edema

\begin{tabular}{|c|c|c|c|c|c|c|}
\hline $\begin{array}{l}\text { J. R. } \\
\text { F. } \\
\text { M. } . \dot{K} . \\
\text { M. G. }\end{array}$ & $\begin{array}{l}59 \\
74 \\
34 \\
53\end{array}$ & $\begin{array}{l}\mathbf{F} \\
\mathbf{M} \\
\mathbf{F} \\
\mathbf{F}\end{array}$ & $\begin{array}{r}82.0 \\
102.3 \\
51.7 \\
61.4\end{array}$ & $\begin{array}{l}34.4 \\
35.4 \\
35.2 \\
27.5\end{array}$ & $\begin{array}{l}42.0 \\
34.6 \\
68.0 \\
44.8\end{array}$ & $\begin{array}{l}\text { A.S.H.D. Emphysema } \\
\text { Myocardial infarct. } \\
\text { H.C.V.D. } \\
\text { H.C.V.D. }\end{array}$ \\
\hline Mean & 55 & & 74.4 & 33.1 & 47.4 & \\
\hline S.D. & & & & & \pm 14.3 & \\
\hline
\end{tabular}

Pace, Kline, Schachman, and Harfenist $(10)^{3}$ and 0.27 is the fraction of solids in wet tissue. The carcass weight was taken as $56.5 \%$ after subtracting bone minerals. Inserting these values in the formula above, the total body water one would expect to observe with tritium is then approximately $74.5 \%$ of the lean body mass. The correction factor representing the maximum error, i.e., for a lean subject, is $0.73 / 0.745=0.98$. The difference of about $2 \%$ corresponds closely with the average of $2.3 \%$ in the differences in body water volumes observed when antipyrine is compared with tritium, as may be seen in Table II. This correction is not made in Tables II-V, because its exact value de-

8 The value used here is derived from Pace's figures for the nitrogen content of dry, fat-free tissue. pends upon a more exact determination of lean tissue mass in individual cases.

Two facts are worthy of note. First, the magnitude of the error is not changed by the degree of obesity; and second, in edematous states, the error decreases as edema increases. The first is true because adipose tissue does not alter significantly either the amount of exchangeable hydrogen atoms or the volume of body water. The second is evident because as body water increases, the amount of tritium exchanged remains the same.

\section{DISCUSSION}

Radiation dosage is always an important consideration in the utilization of radioactive tracers. Two mc. of $\mathrm{T}_{2} \mathrm{O}$ were selected for use in these 
TABLE $v$

Total body water of patients with portal cirrhosis

\begin{tabular}{l|l|l|l|l|l|l}
\hline Patient & Age & Sex & $\begin{array}{c}\text { Weight } \\
\left(K_{\mathbf{g}}\right)\end{array}$ & $\begin{array}{c}\text { Body } \\
\text { water } \\
\text { (liters) }\end{array}$ & $\begin{array}{c}\text { Body } \\
\text { water } \\
(\%)\end{array}$ \\
\hline
\end{tabular}

A. Without ascites or edema

\begin{tabular}{l|c|c|c|c|c|c}
\hline S. S. & 70 & F & 52.0 & 19.4 & 37.3 & \\
E. K. & 33 & F & 45.6 & 21.5 & 47.2 \\
M. B. & 61 & F & 53.2 & 21.1 & 39.7 \\
A. P. & 30 & F & 81.8 & 30.9 & 50.0 & \\
\hline Mean & 48.5 & & 58.2 & 23.2 & 43.5 \\
\hline S.D. & & & & & \pm 6.0 \\
\hline
\end{tabular}

B. With ascites and/or edema

\begin{tabular}{|c|c|c|c|c|c|c|}
\hline $\begin{array}{l}\text { M. H. } \\
\text { A. B. } \\
\text { M. T. } \\
\text { H. M. } \\
\text { J. E. } \\
\text { J. E. } \\
\text { W. D. }\end{array}$ & $\begin{array}{l}36 \\
60 \\
65 \\
51 \\
47 \\
\\
54 \\
60\end{array}$ & $\begin{array}{l}\mathbf{F} \\
\mathbf{M} \\
\mathbf{F} \\
\mathbf{M} \\
\mathbf{M} \\
\mathbf{M} \\
\mathbf{M}\end{array}$ & $\begin{array}{l}71.9 \\
52.4 \\
80.7 \\
\\
49.6 \\
71.3 \\
59.5 \\
58.1\end{array}$ & $\begin{array}{l}37.8 \\
31.8 \\
59.0 \\
\\
26.6 \\
40.2 \\
\\
31.5 \\
30.4\end{array}$ & $\begin{array}{l}52.6 \\
60.7 \\
63.0 \\
53.7 \\
56.4 \\
\\
53.0 \\
52.3\end{array}$ & $\begin{array}{l}\text { Edema } \\
\text { Ascites } \\
\text { Ascites and } \\
\text { anasarca } \\
\text { Ascites } \\
\text { Ascites and } \\
\text { edema } \\
\text { Ascites } \\
\text { Ascites }\end{array}$ \\
\hline Mean & 53.3 & & 63.3 & 36.8 & 56.0 & \\
\hline S.D. & & & & & $\overline{ \pm 4.3}$ & \\
\hline
\end{tabular}

studies because they would produce a very low radiation dose; yet the specific activity of plasma (body water) gave a counting rate that was greater than background by a factor of 20 to 30 .

Dosage rate and total dose were calculated for a 70 kilogram man using an average beta particle energy of 6 kilovolts and an exponential disappearance of tritium with a half life of 10 days.

The maximum dosage rate, which would occur at the time of injection, is: dosage rate $=(2)$ $\left(3.7 \times 10^{7}\right)(6,000)\left(1.64 \times 10^{-12}\right) /(70)=0.01$ rep./day; where $3.7 \times 10^{7}$ is the number of disintegrations per millicurie sec., and $1.64 \times 10^{-12}$ is a factor for conversion from electron volts per second to roentgen equivalent physical (rep.) per day, assuming 84 ergs per rep.

Total dose was calculated by the formula :

Total dose $=$ dosage rate $\times$ half time $/ \ln 2=(0.01)$ $(10) /(0.693)=0.14$ rep.,

which represents the integration of the dosage rate from the time of injection to infinity. The radiation dose during the first week is considerably less than the generally accepted tolerance level of 0.3 roentgen per week.
The average total body water of the four young normal subjects, given in Table II, was $60.4 \%$ of body weight with tritium and $57.1 \%$ with antipyrine. The older subjects in the normal group, i.e., between 34 and 56 years, in Table III, were found to have somewhat smaller volumes, averaging $52.1 \%$ of body weight, than is usually observed in the late 'teens and early twenties. This difference is undoubtedly greatly influenced by the difference in physical condition of the individuals measured in the two age groups, and is reflected in a correspondingly higher percentage of fat. There is at present, too little data to establish a reliable correlation between body water and age. It is felt that such a correlation would, in any event, be essentially a correlation between fat and age.

Since individuals differ markedly in degree of obesity, the proportion of body water normally present will vary accordingly and thus may mask any positive indication of altered water balance. Body water determinations in disease states consequently appear to be of little value as a quantitative measure of water retention or deficiency unless total fat can be determined independently. As Steele, Berger, Dunning, and Brodie (17) have already stated, an obese person can develop edema and still have a smaller proportion of body water than a lean, normal individual. This explains the lack of a significant difference in the proportion of body water observed in cardiac patients with and without edema, shown in Table IV.

The average percentage of total body water of Group A (Table V), which consists wholly of females, was $43.5 \%$ as compared to $44.6 \%$ for normal females (17). In Group B there are five male patients with an average body water of $55.2 \%$, which is only slightly higher than our figure (52.1\%) for normal males. The two females in this group had total body waters considerably above the average for normal females.

Little emphasis was placed on the measurement of body water turnover in this investigation because of previous work on this aspect of the problem by Pinson and Anderson (12). These investigators, using tritium, found biological half-lives of body water in eight normal subjects on an ad libitum water intake to range from nine to 14 days. These values agree closely with those found by Schloerb, and his associates (11) using deuterium. When the water intake of one of these individuals was 
increased from 2.7 liters/day to 12.8 liters/day, the biological half-life was reduced from 10 days to 2.5 days, illustrating the lability of body water turnover in normal individuals.

The difficulties that confront efforts to interpret body water metabolism in disease states could doubtless be resolved if body fat could be determined at the same time. It seems reasonable that if body water can be expressed relative to lean body mass, its significance in disease could be more clearly defined. Although a method now in development for measuring body fat may be applicable to patients, the existing methods are either not sufficiently reliable, or they are impractical for use with sick subjects.

\section{SUMMARY}

1. Total body water has been determined with tritium labeled water in 57 individuals. Twenty were normal and the remainder were suffering from a variety of disease states.

2. Tritium appears to measure the same water volume as deuterium, averaging 2 to $4 \%$ higher than with antipyrine, and undergoes a similar degree of exchange with organic molecules as does deuterium.

3. The difference between antipyrine and tritium body water volumes is accounted for by exchange of tritium with protein bound hydrogen.

4. Body water determinations vary greatly from individual to individual, the variations in proportion reflecting for the most part variation in body fat. In pathologic states, where the lean body mass cannot be assumed to remain constant in composition, body water determinations are of limited value without a method for quantitating fat.

\section{REFERENCES}

1. Siri, W., Unpublished data.

2. Robinson, C. V., A methane, proportional counting method for the assay of tritium. Rev. Scient. Instruments, 1951, 22, 353.

3. Mitchell, H. H., Hamilton, T. S., Steggerda, F. R., and Bean, $H$. W., The chemical composition of the adult human body and its bearing on the biochemistry of growth. J. Biol. Chem., 1945, 158, 625.

4. Lavietes, P. H., D'Esopo, L. M., and Harrison, H. E., The water and base balance of the body. J. Clin. Invest., 1935, 14, 251.

5. Rathbun, E., and Pace, N., Studies on body composition. I. Determination of total body fat by means of the body specific gravity. J. Biol. Chem., 1945, 158, 667.

6. Osserman, E. F., Pitts, G. C., Welham, W. C., and Behnke, A. R., In vivo measurement of body fat and body water in a group of normal men. J. Appl. Physiol., 1950, 2, 633.

7. Levitt, M. F., and Gaudino, M., Measurements of body water compartments. Am. J. Med., 1950, 9, 208.

8. DaCosta, E., and Clayton, R., Report of the fat and water content and the specific gravity of the total carcass of the albino rat in relation to dietary restriction and rehabilitation. U. S. Army Medical Nutrition Laboratory, Chicago, Report No. 62, Sept., 1949.

9. Morales, M. F., Rathbun, E. N., Smith, R. E., and Pace, N., Studies on body composition. II. Theoretical considerations regarding major body tissue components with suggestions for application to man. J. Biol. Chem., 1945, 158, 677.

10. Pace, N., Kline, L., Schachman, H. K., and Harfenist, M., Studies on body composition. IV: Use of radioactive hydrogen for measurement in vivo of total body water. J. Biol. Chem., 1947, 168, 459.

11. Schloerb, P. R., Friis-Hansen, B. J., Edelman, I. S., Solomon, A. K., and Moore, F. D., The measurement of total body water in the human subject by deuterium oxide dilution. J. Clin. Invest., 1950, 29, 1296.

12. Pinson, E. A., and Anderson, E. C., The body absorption, distribution and excretion of tritium in man and animals. The Atomic Energy Commission. Report LA-1218, March 12, 1951.

13. Brodie, B. B., Axelrod, J., Soberman, R., and Levy, B. B., The estimation of antipyrine in biological materials. J. Biol. Chem., 1949, 179, 25.

14. Soberman, R., Brodie, B. B., Levy, B. B., Axelrod, J., Hallander, V., and Steele, J. M., The use of antipyrine in the measurement of total body water in man. J. Biol. Chem. 1949, 179, 31.

15. Pace, N., Unpublished data.

16. Ussing, $H$. $H$., The exchange of $H$ and $D$ atoms between water and protein in vivo and in vitro. Skandinav. Arch. f. Physiol., 1938, 78, 225.

17. Steele, J. M., Berger, E. Y., Dunning, M. F., and Brodie, B. B., Total body water in man. Am. J. Physiol., 1950, 162, 313. 